\title{
Primerjalno o literarni večjezičnosti v slovenskem in avstrijskem kontekstu
}

Alenka Koron in Andrej Leben, ur.: Literarna večjezičnostv slovenskem in avstrijskem kontekstu. Ljubliana: Založba ZRC, 2020. (Studia litteraria 26). 324 str.

\section{Vita Žerjal Pavlin}

Srednja šola za oblikovanje in fotografijo Ljubljana, Gosposka 18, 1000 Ljubljana, Slovenija https://orcid.org/0000-0002-1501-9877

vita.zerjal-pavlin@guest.arnes.si

Obravnavana kolektivna monografija, ki se "tematsko umešča na presečišče literarnovedne slavistike, nemcistike, romanistike in komparativistike« (9), predstavlja razširjeno in dopolnjeno objavo prispevkov s simpozija »Literarna večjezičnost v Avstriji in Sloveniji«, ki je potekal aprila 2018 v Gradcu v organizaciji tamkajšnjega univerzitetnega Inštituta za slavistiko in ZRC SAZU. Kot se za to raziskovalno temo spodobi, slovenska monografija predstavlja tandem nemški, ki je izšla že leta 2019 pri založbi Franke/Narr/Attempo v zbirki Literarische Mehrsprachigkeit / Literary Multilingualism.

Posebnost predstavljene monografije je nedvomno njen primerjalni značaj. Prispevki devetnajstih raziskovalcev in raziskovalk obravnavajo literarno večjezičnost $\mathrm{v}$ kontekstu slovenskega in avstrijskega literarnega sistema (deloma pa $\mathrm{z}$ obravnavo literature slovenske manjšine v Italiji tudi italijanskega oziroma pri obravnavi italijanske v Istri ob slovenskem še hrvaškega), ob tem pa položaj znotraj enega konteksta neposredno primerjajo $s$ položajem $\mathrm{v}$ drugem/-ih ali pa to primerjavo ob branju izpelje kar bralec.

Osnovne značilnosti avstrijskega in slovenskega konteksta literarne večjezičnosti, njune podobnosti in razlike $\mathrm{v}$ uvodu monografije predstavita urednika Alenka Koron in Andrej Leben. Opozorita, da nacionalnoidentifikacijska funkcija literature, ki še danes vpliva na položaj literature narodnih manjšin in priseljencev na Slovenskem (o čemer v nadaljevanju piše Lidija Dimkovska), ni (bila) brez vpliva niti na avstrijsko zavest. Zato se je vključevanje slovenske koroške književnosti ter književnosti migrantov $\mathrm{v}$ avstrijski literarni sistem začelo pozno, in sicer šele od devetdesetih let 20. stoletja, ko je izšla večjezična antologija lirike manjšinskih in priseljenskih pesnikov in pesnic, predvsem pa $\mathrm{v}$ začetku 21. stoletja. Tudi slovenska literarna znanost se je $s$ temami 
literarne večkulturnosti in večjezičnosti začela ukvarjati v začetku 21. stoletja, vendar urednika vseeno ugotavljata, da se pri nas "niti v slovenistični niti $\mathrm{v}$ slavistični stroki niti $\mathrm{v}$ primerjalni književnosti doslej še ni izoblikovalo samostojno raziskovalno področje, ki bi se ukvarjalo predvsem z večjezičnostjo." (13) Obravnavana monografija je vsekakor lahko dodatna spodbuda in temelj za oblikovanje takega področja.

Vključevanje literarnih del, ki niso pisana v večinskem jeziku države, $\mathrm{v}$ oba literarna sistema pa ne pomeni le njihove obravnave $\mathrm{v}$ okviru avstrijske oziroma slovenske literarne zgodovine (čeprav je tudi to še v povojih) ali zgolj njihovega prevajanja in objavljanja pri domačih založbah (kar v obeh obravnavanih kontekstih ni samoumevno) ter $s$ tem dostopnosti za bralsko večino, temveč tudi različne statutarne prilagoditve znotraj avstrijskih oziroma slovenskih literarnih inštitucij, na primer spremembe pravil za podelitev pomembnih nacionalnih nagrad in priznanj ali za vključitev v nacionalna združenja pisateljev. Taka sprememba je bila potrebna, da je Florjan Lipuš lahko 2013 prejel graško literarno nagrado Franza-Nabla in nato leta 2018 še Veliko avstrijsko državno nagrado, najvišje avstrijsko odlikovanje na področju kulture.

Za slovenski kontekst urednika nasprotno navajata, da se Maja Haderlap ne bi mogla potegovati za nagrado kresnik, saj je svoj roman Angel pozabe napisala v nemščini in je bil v slovenščino le preveden. Primera sicer še zdaleč nista istovrstna (Maja Haderlap seveda ni predstavnica nemške manjšine v Sloveniji), kar pa ne izključuje njenih nemško pisanih in v slovenščino prevedenih del (romana in pesmi) iz interesa slovenskih bralcev, kulture ter ustreznih inštitucij s slovensko literarno vedo vred. $\mathrm{Na}$ to kaže tudi $\mathrm{v}$ zborniku omenjena odločitev maturitetne komisije, ki je prevod njenega romana sprejela za maturo iz slovenščine 2018 ter - kar v zborniku ni zabeleženo - nagrada Mira slovenskega centra PEN za avtorico leta 2014. Statutarno spremembo pa je že izpeljalo Društvo slovenskih pisateljev, ki je leta 2012 omogočilo včlanitev avtorjev in avtoric, pišočih v Sloveniji, vendar v tujih jezikih, kot sta Erica Johnson Debeljak in Lidija Dimkovska, tudi avtorica prispevka $\mathrm{v}$ monografiji in urednica antologije sodobne manjšinske in priseljenske književnosti v Sloveniji (2014), ki jo je izdalo prav DSP. Institucija, ki pri nas omogoča redno objavo priseljenskim avtorjem v reviji Paralele in udeležbo na srečanju Sosed tvojega brega, je Javni sklad Republike Slovenije za kulturne dejavnosti, vendar Lidija Dimkovska opozarja, da ostaja krog bralcev te literature zelo ozek, založbe pa nimajo zbirk s priseljensko književnostjo. Prav tako ni nagrad (na višji ravni) za dela $\mathrm{v}$ neslovenskem jeziku, tujejezični pisci se ne morejo potegovati za pisateljske štipendije, sredstva za mobilnost ali rezidenčne štipendije iz 
državnega proračuna. S tem izločanjem izgublja tudi slovenska književnost, je prepričana Dimkovska, ki meni, da neslovensko pišoči književnik, ki živi v Sloveniji, ni dolžan zamenjati jezika (se asimilirati), da bi se integriral v slovensko književnost, mora pa biti prevajan in objavljati (tudi) v slovenščini - kot to počne sama.

V uvodnem zapisu urednikov me je ob ugotovitvi, da se v Sloveniji kljub nekaterim spremembam za tujejezične avtorje »strukturni in institucionalni pogoji za pospeševanje in distribucijo drugo- in večjezične literature niso bistveno spremenili« (14), presenetilo njuno obžalovanje, da Slovenija "ne premore nobenega foruma, ki bi bil primerljiv z dunajskim društvom Verein Exil, s platformo Initiative Minderheiten" (14). Ta, kot pojasnita $\mathrm{v}$ opombi, od leta 1997 podeljuje nagrado, namenjeno »nemško pišočim avtoricam in avtorjem, ki jim nemščina ni prvi jezik«, in objavlja "nagrajene nemško pišoče priseljenske in manjšinske avtorje in avtorice» (14). Tovrstne pobude po mojem mnenju niso namenjene spodbujanju literarne večjezičnosti, ampak ustvarjajo ugodne pogoje za čim hitrejšo (vsaj jezikovno) literarno asimilacijo in literarno enojezičnost $\mathrm{z}$ (verjetno) medkulturno tematiko.

Sicer pa (nemško pisano) književnost migracij v avstrijskem kontekstu Sandra Vlasta v prispevku opredeljuje tematsko, neodvisno od biografije avtorja (čeprav so vsi obravnavani avtorji priseljenci), in ugotavlja, da ta žanr nujno vključuje mnoge oblike literarne večjezičnosti, kar različno vpliva na recepcijo.

Monografske prispevke začenja razprava Marka Juvana, ki ob primerih iz slovenske kulture ponazori prehod od predsistemske večjezičnosti do enojezičnosti v sistemu nacionalne literature s poenotenim knjižnim jezikom. Prepričljivo ga pojasni kot redukcijo kompleksnosti okolja, značilno za vsak sistem. Zato se tudi na ravni svetovnega literarnega sistema, "ki ga zaznamuje institucionalna asimetrija med konsekracijskimi jedri in podrejenimi obrobji, / .../ mnoštvo jezikov prek prevodne in založniške dominacije na mednarodnem trgu začne krčiti, požira ga en sam globalni jezik" (39). In čeprav so obrobja kulturnih sistemov, ki spodbujajo večjezičnost, po Bahtinu, Lotmanu in EvenZoharju razvojno dinamična in ideološko pluralna, Juvan meni, da je za večjezičnost kot izraz enakovrednosti ljudi potrebno "v naprednih družbenih praksah razviti drugačen teoretski jezik, ga uveljaviti v javnosti in v njem zasnovati alternativni ekosistem" (40).

Med ta prizadevanja sodi že naslednji prispevek Jeanne E. Glesener, ki opozori na novo mednarodno področje raziskav malih književnosti (v katero je aktivno vključena tudi slovenska literarna veda) in po kronološkem pregledu teoretskih pristopov $\mathrm{k}$ tej tematiki in uporabljenih 
terminov zanjo (med katerimi je med najvplivnejši izraz "manjšinska književnost" Deleuza in Guattarija) ter predlagane tipologije malih evropskih književnosti (po kateri slovenska književnost - zadnjih trideset let - sodi med književnosti malih držav) v zaključku navede nekaj stališč, $s$ katerimi odpira nadaljnje raziskovalno ukvarjanje $s$ tematiko. Tako zapiše, da bi bilo "za razumevanje 'majhnih književnosti' najbolje, če izhajamo iz kvantitativnih/empiričnih kriterijev in nato na tej osnovi izluščimo in analiziramo njihove specifične diskurze, teme in žarišča" (55), s čimer bi morda lahko izstopili iz paradigme centra in periferije, »da imajo male književnosti druge dinamike in značilnosti in morda celo lastno estetiko« (56) ter da bi bilo "pomembno bolj poudariti literarnoteoretski potencial malih književnosti na področju pluralistično zasnovanega literarnega razvoja» (56).

Eden od terminov, na katerega opozori ta prispevek, je tudi medregionalna književnost, ki izhaja iz pojma medregionalnosti, kot ga je za »jezikovni in kulturnoprostorski položaj literarne kulture na področju Alpe-Jadran« in za obravnavo književnosti tega prostora "tako pod ravnijo nacionalne književnosti (na ravni regije) kot nad njo« (46) že konec osemdesetih let 20. stoletja razvil Janez Strutz s celovške komparativistike, ki želi tudi s prispevkom v tem zborniku spodbuditi komparativistično obravnavo te regije. Njegov koncept Andrej Leben v prispevku opredeli kot temeljnega za model nadregionalnega literarnega interakcijskega prostora (ki pa ni več vezan na geografski prostor), kot so ga zaradi vse večje deregionalizacije literature koroških Slovencev ob različnih sodobnih teoretskih osnovah razvili na Inštitutu za slavistiko Univerze v Gradcu. V zborniku ga uporabi tudi Felix Oliver Kohl, ki ob primerih pokaže, »da koroškoslovenski avtorji za biografska prikazovanja predstavljajo problem « (119). Tako slovenski kot tudi nemškojezični prostor si te avtorje "namreč lastita, obenem pa jih tudi zavračata" (119), kar pomeni, da $\mathrm{v}$ teh prikazih ni omenjena njihova literarna večjezičnost. Podoben problem predstavljajo tudi avtorji in avtorice iz preteklosti, npr. Zofka Kveder, ki je kljub svoji usodi migrantke in literarni večjezičnosti v nemškem geslu na Wikipediji označena samo kot slovenska pisateljica, na kar opozarja Alexandra Millner.

Sodobna deregionalizacija literature koroških Slovencev, pojasnjuje Andrej Leben, pomeni, da precej slovenskih avtorjev ne živi več na Koroškem in objavljajo pretežno ali izključno v nemščini, prihajajo pa $\mathrm{v}$ ta prostor slovensko pišoči iz Slovenije ter drugačnega porekla, ki se »V svojih praviloma $v$ nemščini napisanih besedilih izrecno navezujejo na dvojezični prostor« (61) Koroške. Zato »lahko samo še pogojno govorimo o 'slovenski literaturi'« (61), kar zelo boleče in ogorčeno občuti 
Florjan Lipuš, katerega prozni opus - ugotavlja Silvija Borovnik - je upor zoper izganjanje in izginjanje slovenstva na avstrijskem Koroškem.

Leben razloge za te spremembe na avstrijskem Koroškem strne v zapis, da "so se pogoji na ravni produkcije, distribucije in recepcije te literature zaradi splošnega družbenega razvoja ter novih tehničnih, komunikacijskih in medijskih pogojev in zaradi povečane mobilnosti avtoric in avtorjev temeljito spremenili« (61). Razlogov torej ne problematizira, saj kot eno od prednosti oblikovanega modela, za potrebe katerega je nastala »obsežna elektronska podatkovna zbirka $\mathrm{z}$ več kot 18.500 vnosi, ki vsebuje knjižne objave (primarna besedila, prevode, antologije, izbore) po letu 1990« (63) ter še raznovrstno drugo gradivo, navede prav možnost izogniti se "problematičnim pojmom, kot so nacionalna, narodnostna ali manjšinska literatura«, ob tem pa prispevati »k večji vidnosti socialnih in literarnih praks, ki načenjajo uveljavljene rede in konvencije» (69).

Te prakse, med katerimi ni le nemško enojezično, temveč tudi večjezično in intermedialno ustvarjanje mlajše generacije koroških Slovencev, ponazori Dominik Srienc z avtorji, kot sta Verene Gotthardt, ki je leta 2013 izdala digitalno-analogno dvojezično pesniško zbirko in na svojem blogu objavlja fotografije, videe ter slovensko, nemško in deloma francosko literaturo, ali Nikolaj Efendij z nemškim romanom in vzporedno zgoščenko z angleško-slovenskimi pesmimi, ki tematizirajo isto zgodbo.

Osebno in kot koroški Slovenec tudi prizadeto pa Janez Strutz $\mathrm{v}$ zborniškem prispevku predstavi svoje literarnovedno raziskovanje regionalne večjezičnosti v prostoru Alpe-Jadran, katerega večjezičnost kljub občutju utopičnosti vidi tudi kot možnost za obstoj avstrijskokoroške regionalne dvojezičnosti, »saj bi nam drugače ostala le možnost, da bi žalovali za izgubo stare regionalne raznolikosti« (230). In ko poskuša ob izkušnji svoje domače, nekoč pretežno slovenske vasi pojasniti, kaj je med šestdesetimi in sedemdesetimi leti 20. stoletja privedlo do tega, da se je slovenščina umaknila iz javnosti, navede vpliv televizije, a seveda še usodnejši avstrijski politični pritisk in asimilacijo od koroškega plebiscita ter med drugo svetovno vojno in s tem povezane povojne travme in stigmatizacijo Slovencev. Hkrati navaja podobne politične pritiske $\mathrm{v}$ istem zgodovinskem času tudi drugod v prostoru Alpe-Jadran, ${ }^{1}$ ne navede pa, ali je enak tudi

${ }^{1}$ Prav zaradi osredotočenosti na prostor Alpe-Jadran (tj. pravzaprav avstrijski del nekdanje Avstro-Ogrske) je iz obravnave v zborniku verjetno - v uvodu ni komentarja o tem - izključen slovenski prekmurski prostor z zanimivo slovensko dvokodnostjo (knjižni jezik in narečje oz. stari prekmurski knjižni jezik) ter dvojezičnostjo (slovensko-madžarsko). 
njihov vpliv na sodobno rabo manjšinskega maternega jezika v javnosti oziroma literaturi.

Prispevka Mirana Košuta in Nives Zudič Antonič kažeta, da ne. Košuta ugotavlja, da so med 60 sodobnimi slovenskimi pisatelji v Italiji z vsaj eno knjigo zgolj italijansko pišoči predvsem tisti iz Benečije in Rezije, ki jim ni bilo omogočeno niti osnovno šolanje $\mathrm{v}$ slovenščini. Zelo malo je tudi takih, ki izmenično ustvarjajo tako v maternem kot $\mathrm{v}$ italijanskem jeziku, kar avtor poveže z zahtevnostjo enakovrednega literarnega dvojezičja. Ob tem dodaja (s šegavostjo, značilno zanj), da so dvojezični literati izključno slovenskega ali mešanega rodu, »saj ni doslej zabeležen niti en sam obratni primer v slovenščini literarno pišočega Italijana" (195). Po predstavljeni tipologiji literarne dvojezičnosti ugotavlja še dve skupini: nekateri literati sicer ustvarjajo v italijanščini (Košuta meni, da zaradi pomanjkanja jezikovne samozavesti), a se občasno sami prevajajo $\mathrm{v}$ slovenščino in drugi, ki ustvarjajo v materinščini, pa se občasno sami iz različnih razlogov prevajajo $\mathrm{v}$ italijanščino. $S$ tem si lahko odgovori na uvodoma zastavljeno "problematično" vprašanje o literarni večjezičnosti v italijanskem "predmejstvu" (kot se izrazi), in sicer ali gre "zgolj za osamljeno, osebno umetniško izbiro jezikovno nadizobraženih in večkulturno kompetentnih piscev ali tudi za splošnejši literarni odsev socialno napredujoče narodnostne asimilacije Slovencev v Italiji« (190). Za primerjavo s slovensko manjšino na avstrijskem Koroškem (ki jo naredi tudi Košuta) in obravnavo literarne večjezičnosti sploh je po mojem mnenju zelo pomembno tudi naslednje vprašanje: »Kakšni vzgibi sprožajo in podžigajo tovrsten literarni 'code-switching': identitetni, kulturni, izobrazbeni, tržni, recepcijski? « Ob tem pa tudi Košuta ugotavlja, da prav literati iz manjšinskih večjezičnih okolij predstavljajo literarni vedi različne izzive, med temi potrebo po novih, kompleksnejših, nadjezikovnih ipd. oblikah literarnovedne sistematizacije.

Tudi za književnike italijanske manjšine v Istri in Kvarnerju Zudič Antonič zapiše, da je ustvarjanje $\mathrm{v}$ materinščini (ob občasnem pisanju v slovenščini oz. hrvaščini), pogosto $v$ eni od dveh narečnih oblik ali v knjižni zvrsti, ki pa večkrat vključuje tudi izraze iz drugih dveh jezikov tega območja, »eksistenčna nuja in osnova za preživetje narodnosti« (218). Med tematskimi značilnostmi te literature je - razumljivo - opazna tema »o osebni identiteti, o krizi identitete, notranjih konfliktih, generacijskih konfliktih, nerazumevanju, zvestobi tradiciji ali uporu, dvojni identiteti« (212). Za prevajanje teh besedil v jezik večine skrbi manjšinska organizacija Italijanska unija Istre in Reke, nekatera dela pa so prevedle tudi slovenske založbe. Podobno bi o vlogi 
manjšinskih založb v Italiji lahko zapisal Košuta, saj te, kot vemo, skrbijo tako za izdajanje manjšinskih avtorjev v slovenščini kot za prevode njihovih del v italijanščino.

Tovrstno dvojezičnost gojijo tudi slovenske založbe v Avstriji, ugotavlja Elena Messner, predvsem Mohorjeva družba. Založba Drava je pomembno delo opravila $\mathrm{v}$ devetdesetih letih 20. stoletja $\mathrm{z}$ izdajanjem spominske literature koroških Slovencev v izvirnikih in prevodih. Poleg tega sta si Drava in Wieser "ustvarili mednarodni ugled prav s sistematičnim prevajanjem slovenske književnosti v nemščino« (74), kar je odprlo "vrata srbohrvaški literaturi in kasneje literaturam jugovzhodne Evrope« (158). Avtorica opozarja na posredniško delo teh založb, podprto z različnimi finančnimi podporami, kot je na primer sklad Traduki. Wieser omenja tudi kot založbo, ki odkriva še neuveljavljene avtorje, ki po uveljavitvi preidejo k večjim (nemškim) založbam. Erwin Köstler dodaja, da so te založbe privlačne tudi za objavljanje nemško pišočih, zato "nanje ne moremo več gledati kot na v prvi vrsti manjšinske založbe« (74).

Kar nekaj avtorjev v zborniku obravnava različne oblike literarne večjezičnosti na besedilni ravni, npr. jezikovno preklapljanje, mešanje jezikov ali latentno- in meta-večjezičnost: Erwin Köstler, Sandra Vlasta, Dominik Srienc, Nives Zudič Antonič ter Alenka Koron. Slednja ob opusu Josipa Ostija, ki je kot priseljenec v Slovenijo svojo literarno materinščino kmalu zamenjal za slovenščino, sicer jezik svojega deda, ter v romanih Čefurji raus! in Figa Gorana Vojnovića, predstavnika druge generacije imigrantov iz drugih republik nekdanje skupne države, analizira jezikovno preklapljanje in tematiko večkulturnosti kot "alternativo etnonacionalizmu in šovinizmu (174). Kot ugotavlja, oba avtorja s tem prispevata $\mathrm{k}$ zavesti, da slovenski kulturni prostor ni enojezičen. Iz več razprav je mogoče razbrati, da po večjezičnosti pogosto posegajo tudi sodobni dramatiki, kar kažejo primeri iz Istre in $\mathrm{z}$ avstrijske Koroške, vse bolj tudi dramsko ustvarjanje Petra Handkeja, ki ga predstavlja Vanessa Hannesschläger.

Monografijo zaključujejo prispevki z obravnavo večjezičnosti v preteklosti obravnavanih kontekstov. Alexsandra Millner ga ob osrednji temi t. i. transdiference omenja pri nemško govorečih pisateljicah migrantkah v Avstro-Ogrski, med katerimi je bila tudi Zofka Kveder, Matjaž Birk in Sašo Zver ob literarnih konstrukcijah identitete v časopisu Marburger Zeitung med prvo svetovno vojno, ki je silila k identitetnim premikom $\mathrm{k}$ monokulturnosti tudi avtorje z jezikovne meje, Miran Hladnik pa predstavi slovensko-nemško literarno dvojezičnost (domačinov, tudi Prešerna) v 19. stoletju. Ugotavlja še, da je bila 
nemška književnost na Slovenskem »količinsko skromna, priložnostnega značaja in lokalnega pomena " (294). Ob sodobnem legitimnem vključevanju nemških del, nastalih na Slovenskem, v slovensko literarno zgodovino pa smiselno zaključi, da ta del ni bil spregledan po krivici, temveč zato, ker je bil osrednjemu slovenskemu prizadevanju dejansko nevaren. „Nemška literatura na Slovenskem namreč ni nastajala iz kakšnih multikulturnih pobud, ampak da bi ohranila privilegije dominantnega jezika nemšcine, rastla je iz boja med nemškim in slovenskim kulturnim monopolizmom« (294).

Zbornik $s$ tem zaključnim prispevkom dodatno opozori na družbeno-politične pogoje za večjezičnost literature v konkretnem kulturno-političnem prostoru. Sodobni globalni »kontekst «, kot se uresničuje znotraj Slovenije in Avstrije in kot razkrivajo prispevki, družbeno ter literarno večjezičnost sicer načeloma in vsaj deloma tudi strukturno ter finančno podpira. Vseeno odločitev literatov za uporabo maternega literarnega jezika $\mathrm{v}$ okoljih $\mathrm{z}$ drugim večinskim jezikom iz različnih razlogov ni lahka, in to ne samo za migrante, temveč celo za pripadnike avtohtonih narodnih manjšin, čeprav jim je danes tako v Sloveniji kot v Avstriji oz. v vseh štirih obravnavanih državnih kontekstih v nasprotju $s$ preteklostjo ta možnost politično omogočena.

1.19 Recenzija / Review

UDK 82.0(436:497.4):81'246.3

821.163.6.09

821.112.2(436).09

D0I: https://doi.org/10.3986/pkn.v44.i3.12 